\title{
Group hypnosis for stress reduction and improved stress coping: a multicenter randomized controlled trial
}

Silvia Fisch ${ }^{1,2}$, Suzana Trivaković-Thiel ${ }^{1,3}$, Stephanie Roll ${ }^{2}$, Theresa Keller ${ }^{4}$, Sylvia Binting ${ }^{2}$, Margit Cree ${ }^{2}$, Benno Brinkhaus ${ }^{2+}$ and Michael Teut ${ }^{2^{*}+}$ (D)

\begin{abstract}
Background: The aim of the trial was to investigate the effect of a hypnotherapeutic group program in healthy persons with increased levels of perceived stress.

Methods: In a randomized controlled multicenter trial participants with a self-assessed subjective stress level $\geq 40$ $\mathrm{mm}$ on a visual analogue scale (0-100 mm; VAS) for the previous week and a stable state of health were randomized to either 5 weekly sessions of 120-min duration of a hypnotherapeutic group program for stress reduction and improved stress coping plus 5 hypnosis audiorecords for individual practice at home plus an educational booklet for stress coping (hypnosis group) versus an educational booklet only (control group). The primary outcome parameter was the VAS stress level for the previous week after 5 weeks. Secondary outcome parameters included the VAS stress level after 12 weeks, perceived stress (CPSS), depression (ADS-K), self efficacy (SWE) and quality of life (SF 36) after 5 weeks and 12 weeks. Analysis of covariance with a significance level of 5\% using the full analysis set was used for analysis; the model included treatment (fixed effect), VAS baseline value (fixed covariate), and center (random effect).
\end{abstract}

Results: A total of 95 participants were randomized; 47 (40 female, $45 \pm 13.4$ years of age) were allocated to the hypnosis group, and 48 (41 female, $46.9 \pm 14.3$ years) were allocated to the control group. Regarding VAS stress level after 5 weeks, the adjusted VAS mean in the hypnosis group was $41.8 \mathrm{~mm}$ [95\% confidence interval (Cl): 35.2; 48.4] compared to 62.9 $\mathrm{mm}[56.2 ; 69.7]$ in the control group, and the group difference was $-21.2 \mathrm{~mm}[-30.1 ;-12.2](P<0.001)$. After 12 weeks, the stress intensity on the VAS showed a between-group difference of $-14.7 \mathrm{~mm}[-25.1 ;-4.4](P=0.006)$, and the adjusted means were $41.1 \mathrm{~mm}$ [33.4; 48.8] in the hypnosis group and $55.9 \mathrm{~mm}[48.4 ; 63.5]$ in the control group. Improvements were also reported for CPSS, SF-36, SWE and ADS-K after 5 and 12 weeks.

Conclusion: Compared to the control group, the hypnosis group showed reduced perceived stress after 5 and 12 weeks. Trial registration: ClinicalTrials.gov NCT03525093; date of registration: May 15, 2018.

Keywords: Hypnosis, Hypnotherapy, Stress reduction, Stress coping, Group program

\footnotetext{
* Correspondence: michael.teut@charite.de

${ }^{\dagger}$ Brinkhaus Benno and Teut Michael contributed equally to this work.

${ }^{2}$ Institute for Social Medicine, Epidemiology, and Health Economics, Charité

-Universitätsmedizin Berlin, Luisenstr. 57, 10117 Berlin, Germany

Full list of author information is available at the end of the article
}

(c) The Author(s). 2020 Open Access This article is licensed under a Creative Commons Attribution 4.0 International License, which permits use, sharing, adaptation, distribution and reproduction in any medium or format, as long as you give appropriate credit to the original author(s) and the source, provide a link to the Creative Commons licence, and indicate if changes were made. The images or other third party material in this article are included in the article's Creative Commons. licence, unless indicated otherwise in a credit line to the material. If material is not included in the article's Creative Commons licence and your intended use is not permitted by statutory regulation or exceeds the permitted use, you will need to obtain permission directly from the copyright holder. To view a copy of this licence, visit http://creativecommons.org/licenses/by/4.0/. The Creative Commons Public Domain Dedication waiver (http://creativecommons.org/publicdomain/zero/1.0/) applies to the data made available in this article, unless otherwise stated in a credit line to the data. 


\section{Background}

Stress and stress-related diseases are considered important health issues worldwide [1-5]. A survey conducted in Europe showed that 20\% of employees experience and perceive a high level of daily stress [3]. In Germany, a survey with 1200 adult respondents indicated that 61\% of Germans reported being stressed often or sometimes, and $58 \%$ of the respondents reported recently feeling more stressed than they did 3 years before [4]. Chronic stress also plays a role in the development and aggravation of physical or mental illnesses. The German survey reported the following: "For respondents who described their state of health as less good or bad, almost one in three individuals often feels under stress. (...) Fifty-three percent of respondents who have had mental health problems in the past three years described themselves as "frequently stressed"' [4]. Popular stress management programs that have been tested for effectiveness are often based on a cognitive-behavioral approach [6-11]. An increasing number of stressed people are turning to complementary therapies, such as yoga, qigong, tai chi, meditation, and mindfulness-based stress reduction (MBSR). The effectiveness of these methods has been partially shown [12]. Additionally, hypnosis has become increasingly popular and has received greater worldwide attention in recent years. Research has shown evidence of the effectiveness of medical hypnosis in the context of several health conditions $[13,14]$. The definition of hypnosis is "a state of consciousness involving focused attention and reduced peripheral awareness characterized by an enhanced capacity for response to suggestion" $[15,16]$. Hypnotherapy is defined as "the use of hypnosis in the treatment of a medical or psychological disorder or concern" $[15,16]$ and currently includes a resource-activating and solution-oriented therapeutic attitude and a hypnosystemic style of speech [17, 18]. Despite many narratively reported positive experiences with using hypnotherapeutic interventions for stress reduction and improving stress-coping skills in the educational literature, there are only a few standardized hypnotherapeutic group programs available. Regarding its potential in stress reduction or prevention, there is currently a lack of high-quality clinical evidence. There are only a few studies that show positive effects of hypnotherapeutic interventions for stress reduction [16].

With the involvement of hypnosis experts, we designed a 5-session hypnotherapeutic group program for stress reduction and improved stress coping in healthy people with a perceived increased stress level in a prior feasibility study [5]. In the pre/post comparison of this exploratory observational study, a reduced stress level and an improvement in stresscoping competences were reported after 5 weeks. The results of this feasibility study led to the hypothesis that the designed hypnotherapeutic group program may reduce stress and improve stress-coping skills [5]. The aim of the present trial was to investigate the effectiveness of the hypnotherapeutic group program for stress reduction and improved stress coping in healthy persons with high levels of perceived stress.

\section{Methods \\ Design}

This study was a 2-armed randomized, controlled, open, multicenter trial performed at four study centers in Germany: 1. Hochschulambulanz für Naturheilkunde (Outpatient Department for Integrative Medicine) der Charité Universitätsmedizin Berlin; 2. a psychotherapeutic clinic in Coesfeld; 3 . the Hospital of the Faculty of Medicine of the Westfälische Wilhelms-Universität, Münster; 4. MEDIAN Center for Behavioral Medicine Department of Psychosomatics (Zentrum für Verhaltensmedizin - Klinik für Psychosomatik) in Bad Pyrmont. The study followed the guidelines for clinical trials and was approved by the ethics committee of the Charité Universitätsmedizin Berlin, Berlin, Germany (Approval No. EA1/067/18). The study was registered at ClinicalTrials.gov (Identifier NCT03525093). Participants provided written informed consent.

\section{Participants}

Participants were eligible, if they fulfilled the following inclusion criteria: $18-70$ years of age, self-assessed subjective stress level $\geq 40 \mathrm{~mm}$ on a visual analog scale $(0$ $100 \mathrm{~mm}$; VAS) for the previous week, a subjective increased level of perceived stress for at least 3 months, a stable state of health, and signed informed consent.

The following exclusion criteria were applied: current or planned participation in another psychological stress reduction program within the next 12 weeks, current use of psychotherapy, presence of moderate or severe acute or chronic disease conditions, and presence of an acute or chronic mental disorder.

Participants were recruited through newspaper advertisements in Berlin and Coesfeld, the website and newsletter of the Charité Outpatient Department for Integrative Medicine and the psychotherapeutic clinic in Coesfeld, the Newsletter of the Studienhospital Münster, and through flyers in the MEDIAN Zentrum Bad Pyrmont.

\section{Study interventions}

After inclusion and baseline assessment, the participants in both groups received a written behavioral stress management educational booklet provided by a German health insurance company [19]. The information booklet (60 pages) contains the sections "recognizing stress", "managing stress" and "preventing stress". The section "recognizing stress" describes the physiological basis of a 
natural activation reaction and conveys various levels of a stress response (cognitive, emotional, vegetative, muscular). In addition, the reader is sensitized to the detection of individual stressors. The section "managing stress" introduces and briefly discusses common stress management strategies such as problem solving, time management, various relaxation techniques, sports, and recognizing and changing unfavorable attitudes. In the third section, "preventing stress," the salutogenesis model is presented and the reader is informed about the structure and promotion of so-called resilience factors (in particular, the maintenance of social contacts). Finally, some short-term stress management strategies are explained, and a suggestion for a training protocol is given $[5,19]$.

The hypnotherapeutic group program was designed and tested in a prior feasibility study [5], and the concepts of the hypnotic trances contained ideas according to different authors [20-27]. It consisted of five standardized sessions covering health education, hypnotic inductions, and therapeutic talk (Table 1). The hypnotherapeutic group program was conducted by certified hypnotherapists ( 2 psychotherapists and 1 family physician) with groups between 8 and 12 participants in size in five weekly sessions of 120 min each. The hypnotherapeutic group program followed a manual with standardized hypnosis instructions that was developed and optimized in the prior feasibility study. In addition, prerecorded audio recordings (either a $\mathrm{CD}$ or downloadable MP3 files) of the hypnosis exercises were handed out to participants at the end of each session for self-practice at home. Participants were free to choose how and when to listen to the audio recordings (headphones, speakers, computers, CD players or other devices).

The intervention was intended to induce relaxation; to identify, activate and experience resources for coping with stressful situations; to develop and train stress-coping skills; and to apply mental training and anchoring [5].

The participants in the control group were offered free participation in the hypnotherapeutic group program after the study.

\section{Randomization}

Patients were enrolled by the study physicians and study psychologists. After signing informed consent, inclusion in the trial, and baseline assessment, the participants were randomized to the intervention or control group in a 1:1 ratio via a central telephone randomization line by an otherwise independent study nurse. The randomization was stratified by center and in blocks of 20 participants (to take into account the group size of 10 people). The random allocation sequence was generated by using SAS 9.4 software (SAS Institute Inc. Cary, NC, USA).

\section{Outcome parameters}

We used questionnaires with self reported outcome measures, which were filled out by patients at home and sent to the study office by post. The primary outcome parameter was the perceived stress level in the previous week on a visual analog scale (VAS; 0-100 mm: 0 no stress, 100 maximum stress) after 5 weeks $[28,29]$. Construct validity can be assumed because of correlations between VAS and the subscales and total score of the Hospital Anxiety and Depression Scale HADS [30] of $0.66,0.45$ and 0.65 , respectively $[28,29]$.

Secondary outcome parameters were VAS stress level after 12 weeks; Cohen's Perceived Stress Scale (CPSS [31, 32];), a 10 items questionnaire that assess the degree to which people perceive their lives as stressful; score 0-40 with higher scores indicate a higher perceived stress level; depression assessed with the "Allgemeine Depressionsskala Kurzform "(ADS-K; score 0-45 with higher scores indicate higher level of depression) [33]; Schwarzer Self-Efficacy questionnaire (score 10-40, with higher scores indicate a better status of self-efficacy) [34]; and generic health related quality of life measured with the SF-36 questionnaire (score 0-100 with higher scores indicate better status of quality of life) [35, 36].

Furthermore, we asked participants about their most important individual goal they wanted to achieve with the hypnotherapeutic group program at baseline. We used Likert scales to assess the participants' personal goal attainment and satisfaction with the intervention after 5 and 12 weeks. During the 12-week study period, the participants recorded the frequency of self-hypnosis exercises each week. After 5 weeks and after 12 weeks, participants were asked about the occurance of any critical life event during the last 5 and 7 weeks, respectively. Adverse events were recorded throughout the study observational period in the intervention and the control group.

\section{Statistics}

Based on the previous feasibility study, we considered the difference in the primary endpoint (last week's perceived stress intensity on a VAS) of $20 \mathrm{~mm}$ between intervention and control as a clinically relevant difference. With these assumptions, for a two-sided t-test with a significance level of $5 \%$, a power of $90 \%$, and an assumed standard deviation of $25 \mathrm{~mm}$, a total of 34 participants per treatment group were necessary (68 in total). To compensate for an expected drop-out rate of approximately $15 \%$, we planned to randomize 40 participants per group (80 in total).

Data analyses were carried out with the SAS for Windows 9.4 (SAS Institute, Cary, NC, USA). Statistical methods were defined in a detailed statistical analysis plan (SAP) before the data analysis. The analysis of the 
Table 1 Themes and procedure of the individual sessions of the hypnotherapeutic group program

\begin{tabular}{lll}
\hline Themes & Procedure & $\begin{array}{c}\text { Duration } \\
\text { (minutes) }\end{array}$ \\
\hline
\end{tabular}

\section{Session}

Introduction to stress coping and · Getting acquainted, promotion of group cohesion and rapport

- Suggestibility test and convincer ("experiment with hypnosis")

a. Ideomotoric trance induction "magnetic hands" [20]

b. Reorientation

- Hypnosis: physical relaxation and mental reassurance

a. Trance induction and deepening: mindful perception of body and posture, focus the attention on breathing [21]

b. Distancing technique: balloon, in which one can let fly away one's disturbing thoughts or themes

c. Relaxation suggestions

d. Mental reassurance: metaphor "mind as a pond" according to Stanton [22]

e. Psychoeducation for the stress and relaxation reaction in a trance to promote the natural autonomic self-regulation

f. Post-hypnotic suggestion to motivate participants to individual practice and homework

g. Reorientation

- Initiate self-employment of hypnosis recordings and farewell

\section{Session}

Resource activation

- Exploration of the experiences with practicing independently at home

- Imparting the principle of the "resource key for stress management"

- Find necessary resources for the specific stressful situations of the participants

- Hypnosis: dissociation from the stress situation and activation of a resource experience

a. Trance induction and deepening: visual fixation, body scan [23, 24]

b. Distancing technique: counting stairs to the resourceful place, box/suitcase to put

off upsetting things or thoughts

c. Resource identification and activation at the "resourceful place"

d. Anchoring of the resource experience with a finger touch [23]

e. Suggestion of helpful attitudes to stress management and achievement orientation

according to Stanton [25]

f. Post-hypnotic suggestion for repeated resource experience

g. Reorientation

- Completing the session and farewell

\section{Session}

Resource key

(Linking stressful situation and resource experience)

\section{Session}

Resource transfer (Experience of successful stress coping)
- Exploration of the experiences with practicing independently at home

- Hypnosis: Repetition of the resource activation from the second session

- Hypnosis: Practicing the rapid occurrence of resource experience

- Hypnosis: Practicing the reflexive triggering of the resource experience through a stress stimulus ("resource key") according to Bongartz' "problem as anchor" [26]

- Completing the session and farewell

- Hypnosis: Mentally anticipating and practicing a successful resource experience in a typical stress situation and coping with the stress situation ("resource transfer")

a. Trance induction and deepening, distancing technique: visual fixation; body scan; thoughts as clouds in the sky; noises, such as a radio in the background [23, 24]; stairs to the resourceful place b. Resource activation "resourceful place"

c. Transfer of the resource experience into the critical situation: experience of successfully coping with the stress situation

d. Post-hypnotic suggestion for successful coping with stress

e. Reorientation

- Completing the session and farewell 
Table 1 Themes and procedure of the individual sessions of the hypnotherapeutic group program (Continued)

\begin{tabular}{|c|c|c|}
\hline Themes & Procedure & $\begin{array}{l}\text { Duration } \\
\text { (minutes) }\end{array}$ \\
\hline \multicolumn{3}{|l|}{ 5. Session } \\
\hline \multirow{4}{*}{$\begin{array}{l}\text { Future progression } \\
\text { (Further improvement } \\
\text { and stabilization) }\end{array}$} & $\begin{array}{l}\text { - Appreciation of the changes in stress coping competences achieved so far and } \\
\text { integration into self-image }\end{array}$ & 45 \\
\hline & $\begin{array}{l}\text { - Hypnosis: Facilitate further improvement and stabilization } \\
\text { a. Trance induction with a marble [27] and deepening } \\
\text { b. Partial age regression: Remembering the most important themes and experiences } \\
\text { during the participation of the group program } \\
\text { c. Age progression into a time in the future when the goal of improved coping with } \\
\text { stress is reached: integration of competencies and characteristics in one's self-image, increased } \\
\text { self-efficacy } \\
\text { d. Anchoring of this experience with a marble [27] } \\
\text { e. Post-hypnotic suggestion for successful coping with stress } \\
\text { f. Reorientation }\end{array}$ & 35 \\
\hline & - Answer open questions and concerns & 20 \\
\hline & - Completion and farewell & 20 \\
\hline
\end{tabular}

primary endpoint was performed by analysis of covariance (5\% significance level), two-sided using the full analysis set (FAS) based on the intention-to-treat (ITT) principle without imputation of missing values; the analysis model included treatment (fixed effect), VAS baseline value (fixed covariate), and center (random effect). All further analyses were evaluated with similar models and were considered exploratory. A sensitivity analysis of the primary endpoint was performed with multiple imputations for missing primary outcome data.

\section{Results \\ Participants}

The study was conducted between May and October 2018. Figure 1 shows the flow diagram of the participants. Of the 95 participants randomized, 47 were

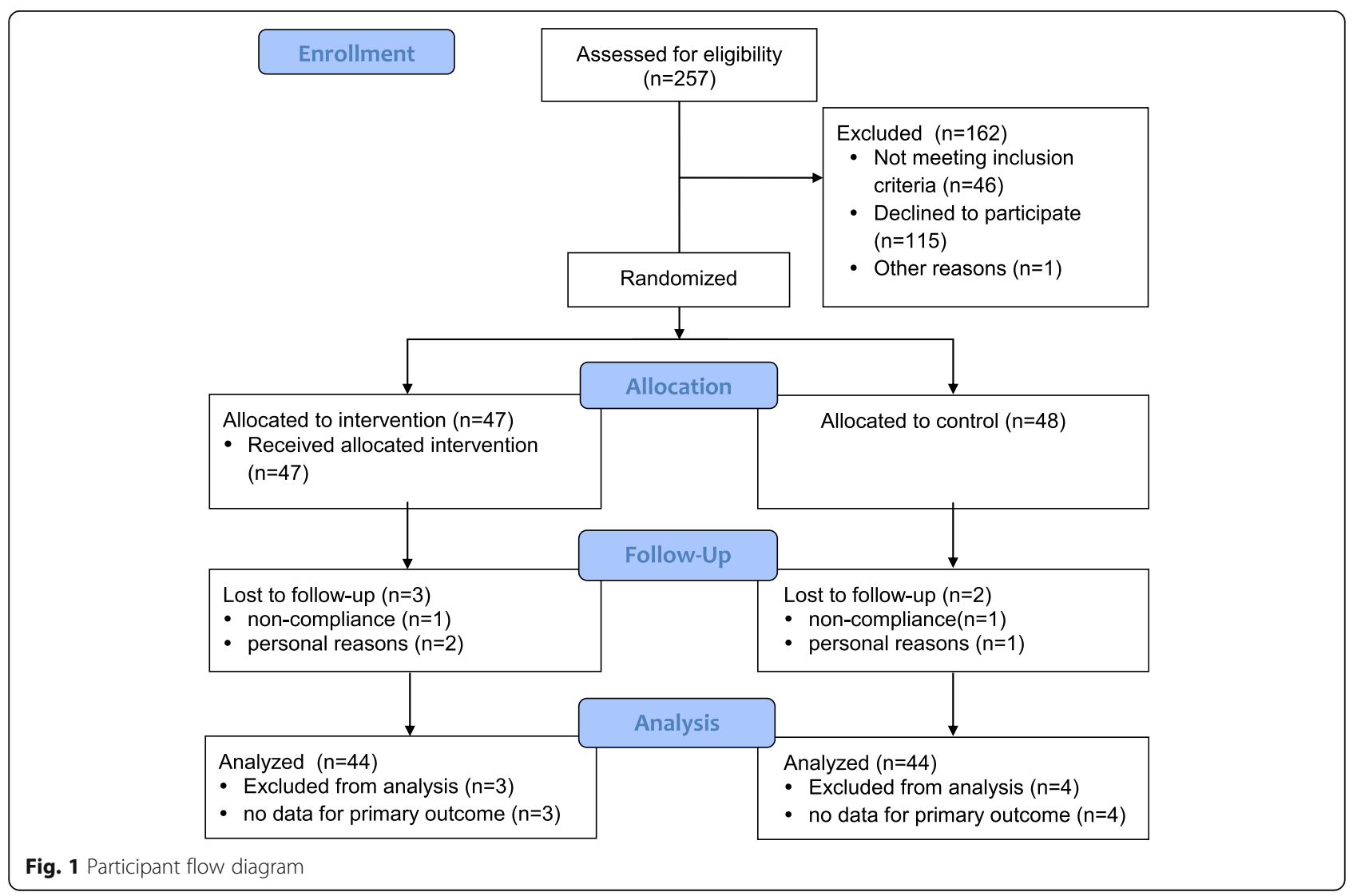


allocated to the hypnosis group and 48 to the control group. At the 12-week follow-up, 5 participants had dropped out of the trial (3 from the hypnosis group and 2 from the control group).

Table 2 shows the sociodemographic characteristics and Table 3 shows the baseline data of the outcome parameters for the participants.

Most health-related parameters showed comparable values at baseline in both groups (Table 3).

\section{Primary outcome parameter}

For the VAS stress intensity after 5 weeks (primary outcome parameter), there was a mean difference between the intervention and control group of $-21.2 \mathrm{~mm}$ [95\% CI: $-30.1 ;-12.2](P<0.001)$, with adjusted VAS means of $41.8 \mathrm{~mm}$ [35.2; 48.4] in the hypnosis group and 62.9 $\mathrm{mm}[56.2 ; 69.7]$ in the control group (Table 4, Fig. 2).

The additional sensitivity analysis of the primary outcome with multiple imputations for missing values showed adjusted means of $42.7 \mathrm{~mm}$ [36.0; 49.4] for the hypnosis group compared to $61.0 \mathrm{~mm}[54.3 ; 67.7]$ for the control group, and the mean difference was -18.3 $\mathrm{mm}[-27.3 ;-9.3](\mathrm{P}<0.001)$.

\section{Secondary outcome parameters}

After 12 weeks, the stress intensity on the VAS showed a between-group difference of $-14.7 \mathrm{~mm}[-25.1 ;-4.4]$ (hypnosis group: 41.1 [33.5; 48.8]; control group: 55.9 [48.2; 63.5]; $P=0.006$ ) (Table 5, Fig. 2). The hypnosis group also showed better values after 5 and 12 weeks for perceived stress (CPSS), depression (ADS-K), selfefficacy (SWE) and quality of life (SF-36 Mental Component Summary), but not on the SF-36 Physical Component Summary. The SF 36 subscores showed betweengroup differences for "Role limitations due to emotional problems", "Emotional well-being", "Vitality", "Social functioning" and "General health perception" (Tables 4 and 5, Fig. 3). The evaluation of the frequencies of the participants who had increased levels of depression on the ADS-K (cut-off $>17$ as a screening for depression, [33]) showed at baseline an increased ADS-K score in $93.6 \%$ of the hypnosis group patients and in $89.6 \%$ of the control group participants. After 5 weeks only $59.1 \%$ of the hypnosis patients had an ADS-K score $>17$ compared to $86.4 \%$ of the control group patients (after 12 weeks $63.6 \%$ of the hypnosis group and $84.1 \%$ of the control group, respectively).

The participants in the hypnosis group stated high satisfaction with the program: after 5 weeks, $27.9 \%$ were satisfied, and $67.4 \%$ were very satisfied; after 12 weeks, $36.4 \%$ were satisfied, and $52.3 \%$ were very satisfied. The participants who completed the hypnotherapeutic group program participated in at least 4 sessions. Most of the participants practiced self-hypnosis with audiorecords
2-3 times per week during the 5-week intervention period. After completion of the group sessions, most participants continued their self-hypnosis practice up to the end of the trial at 12 weeks $(36.4 \%$, once a week; $52.3 \%, 2-3$ times a week; and $11.4 \%, 4-5$ times a week). After 5 weeks, 16 participants of the total sample (18.18\%) reported the occurrence of a critical life event during the last 5 weeks (such as change of job, relocation, illness of a relative, loss of a person), after 12 weeks, 35 participants $(38.89 \%)$ had a critical life event during the last 7 weeks. No adverse events were reported in this trial, that were associated with the intervention.

After 5 weeks, $95.5 \%$ of the hypnosis group stated that their main therapeutic goal was partially or completely achieved $(97.7 \%$ after 12 weeks) compared to $27.9 \%$ in the control group (37\% after 12 weeks) (Fig. 4).

\section{Discussion}

In this multicenter RCT, we observed statistically significant between-group differences in perceived stress intensity on a visual analog scale after 5 weeks and 12 weeks for participants in the hypnotherapeutic group program compared to individuals in the control group, who received only an educational booklet on stress management. In addition, we observed group differences favoring hypnosis in the secondary outcomes, such as perceived stress (CPSS), depression (ADS-K), selfefficacy (SWE), and quality of life (SF-36 Mental Component Summary), after 5 and 12 weeks. The results of the Likert scales for individual goal attainment and satisfaction with the hypnotherapeutic group program after 5 and 12 weeks fit well with the results. They showed that most participants were able to achieve their individual goals and were satisfied with the program. The participants showed good compliance and adherence (attendance and participation in the group sessions and individual practice of self-hypnosis with audio records during the 5 weeks of hypnotherapeutic group program duration and up to the end of the trial at 12 weeks).

While other studies on stress reduction with hypnosis have used interventions with more homogeneous groups (e.g., students, secretaries, high school teachers, or special groups of patients) [22, 25, 37-46] our hypnotherapeutic group program was designed for a wide range of healthy persons with high levels of perceived stress. The intervention was carefully developed by the study team on the basis of a systematic literature review [16] and the involvement of hypnosis experts with extensive experience as hypnotherapists and a broad knowledge of the professional literature on the topic. The hypnotherapeutic group program was conducted by qualified hypnotherapists (physicians or psychological psychotherapists). In comparison with other established stress management trainings using behavioral therapy with 8 to 12 group sessions of $2 \mathrm{~h}$ or 30 to $40 \mathrm{~h}$ in 
Table 2 Baseline demographic characteristics (values are means \pm standard deviations (SD) or absolute numbers (N) and percentages

\begin{tabular}{|c|c|c|c|c|}
\hline & $\mathbf{N}$ & $\begin{array}{l}\text { Hypnosis } \\
N=47\end{array}$ & $\begin{array}{l}\text { Control } \\
N=48\end{array}$ & $\begin{array}{l}\text { All participants } \\
N=95\end{array}$ \\
\hline & & Mean \pm SD / N (\%) & Mean \pm SD / N (\%) & Mean \pm SD / N (\%) \\
\hline Age [years] & 95 & $45.0 \pm 13.4$ & $46.9 \pm 14.3$ & $46.0 \pm 13.8$ \\
\hline Sex [female] & 95 & $40(85.1)$ & $41(85.4)$ & $81(85.3)$ \\
\hline \multicolumn{5}{|l|}{ Education } \\
\hline Abitur (German university entrance qualification) & 95 & $36(76.6)$ & $37(77.1)$ & $73(76.8)$ \\
\hline Vocational education [university] & 95 & $14(29.8)$ & $15(31.3)$ & $29(30.5)$ \\
\hline \multicolumn{5}{|l|}{ Employment } \\
\hline Employed [yes] & 95 & $41(87.2)$ & $39(81.3)$ & $80(84.2)$ \\
\hline Full-time employee & 80 & $20(48.8)$ & $14(35.9)$ & $34(42.5)$ \\
\hline Part-time employee & & $21(51.2)$ & $25(64.1)$ & $46(57.5)$ \\
\hline Part-time because of stress [yes] & 44 & $4(20.0)$ & $7(29.2)$ & $11(25.0)$ \\
\hline Incapacity for work last 4 weeks [no] & 79 & $35(87.5)$ & $31(79.5)$ & $66(83.5)$ \\
\hline Size of household (more than single) & 95 & $36(76.6)$ & $38(79.2)$ & $74(77.9)$ \\
\hline \multicolumn{5}{|l|}{ Health parameter } \\
\hline BMl & 95 & $23.3 \pm 3.9$ & $24.4 \pm 4.2$ & $23.8 \pm 4.1$ \\
\hline Smoking [yes] & 95 & $7(14.7)$ & $9(18.8)$ & $16(16.8)$ \\
\hline Alcohol [yes] & 95 & $37(78.7)$ & $39(81.3)$ & $76(80.0)$ \\
\hline Sports [yes] & 95 & $44(93.6)$ & $46(95.8)$ & $90(94.7)$ \\
\hline Sport frequency [1-2 times weekly] & 90 & $23(52.3)$ & $21(45.7)$ & $44(48.9)$ \\
\hline Stressful lifetime event in the last 6 months [yes] & 95 & $21(44.7)$ & 19 (39.6) & $40(42.1)$ \\
\hline Number of stress symptoms & 95 & $\begin{array}{l}8.7 \pm 7.1 \\
\text { Range 3-39 }\end{array}$ & $\begin{array}{l}8.4 \pm 5.6 \\
\text { Range 3-25 }\end{array}$ & $\begin{array}{l}8.6 \pm 6.4 \\
\text { Range 3-39 }\end{array}$ \\
\hline \multicolumn{5}{|l|}{$\begin{array}{l}\text { Stress factors } \\
\text { (multiple choices possible) }\end{array}$} \\
\hline \multicolumn{5}{|l|}{ Professional requirements } \\
\hline Job/University & 95 & $33(70.2)$ & $28(58.3)$ & $61(64.2)$ \\
\hline Exam preparation & 95 & $10(21.3)$ & $8(16.7)$ & $18(19.0)$ \\
\hline High demands on oneself & 95 & $35(74.5)$ & $33(68.8)$ & $68(71.6)$ \\
\hline Conflicts with colleagues / superiors & 95 & $6(12.8)$ & $9(18.8)$ & $15(15.8)$ \\
\hline Time pressure, high density of appointments & 95 & $32(68.1)$ & $16(33.3)$ & $48(50.5)$ \\
\hline \multicolumn{5}{|l|}{ Private requirements } \\
\hline Private conflicts & 95 & $18(38.3)$ & $17(35.4)$ & $35(36.8)$ \\
\hline Parenting & 95 & $9(19.2)$ & $6(12.5)$ & $15(15.8)$ \\
\hline Disease (close people) & 95 & $13(27.7)$ & $10(20.8)$ & $23(24.2)$ \\
\hline Care of a relative & 95 & $5(10.6)$ & $3(6.3)$ & $8(8.4)$ \\
\hline Household & 95 & $9(19.2)$ & $4(8.3)$ & $13(13.7)$ \\
\hline Money worries & 95 & $5(10.6)$ & $7(14.6)$ & $12(12.6)$ \\
\hline Preparation special events & 95 & $5(10.6)$ & $4(8.3)$ & $9(9.5)$ \\
\hline \multicolumn{5}{|l|}{ Adversities of everyday life/daily hassles } \\
\hline Organization of everyday life & 95 & $13(27.7)$ & $11(22.9)$ & $24(25.3)$ \\
\hline Public transport & 95 & $7(14.9)$ & $8(16.7)$ & $15(15.8)$ \\
\hline Doctor visits & 95 & $6(12.8)$ & $4(8.3)$ & $10(10.5)$ \\
\hline Waiting & 95 & $1(2.1)$ & $6(12.5)$ & $7(7.4)$ \\
\hline
\end{tabular}


Table 2 Baseline demographic characteristics (values are means \pm standard deviations (SD) or absolute numbers (N) and percentages (Continued)

\begin{tabular}{|c|c|c|c|c|}
\hline & $\mathbf{N}$ & $\begin{array}{l}\text { Hypnosis } \\
N=47\end{array}$ & $\begin{array}{l}\text { Control } \\
N=48\end{array}$ & $\begin{array}{l}\text { All participants } \\
N=95\end{array}$ \\
\hline & & Mean \pm SD / N (\%) & Mean \pm SD / N (\%) & Mean \pm SD / N (\%) \\
\hline Become disturbed / interrupted & 95 & $16(34.0)$ & $7(14.6)$ & $23(24.2)$ \\
\hline Other & 95 & $10(21.3)$ & 17 (35.4) & $27(28.4)$ \\
\hline
\end{tabular}

$N$ numbers, $S D$ standard deviation, $B M I$ body mass index $\left(\mathrm{kg} / \mathrm{m}^{2}\right)$

different course modules [7-9], our program is less time intensive. This might be of interest for healthy people, who already feel stressed and are looking for support to improve their stress management skills with manageable time requirements.

A limitation of this study is the impossibility of blinding the interventions, which could have introduced bias. The control group design, although providing a behavioral educational booklet for the control group, provided no control in regard to time, interpersonal contact, and expectancy. So it is impossible to assess which components of the intervention had a specific effect in reducing stress. Possible effect mechanisms of the intervention could have been the amount of time spent with the topic of stress reduction, the experience of group hypnosis, therapeutic expectations and suggestions, participating in a group with its group discussions and mutual support, received attention through the physician/psychotherapist, the hypnotherapeutic communication, and the individual self-hypnosis training at home. The low number of males participating in the hypnosis training and $85 \%$ female participation is particularly striking but consistent with the sex frequency distribution in our pilot study $(86 \%,[5])$ and with the experience in other studies with complementary medical interventions $[16,47]$. It can be assumed that women may be more interested in hypnosis and more willing to participate than men. The education level, with $76.8 \%$ of participants completing German Abitur (high school), is also high. It is thus unclear whether the intervention would also be effective for a male population and for participants with a lower educational level.

Another weakness of the study is, that we did not assess the hypnotizability of participants in the hypnosis group by means of a suggestibility scale at baseline to

Table 3 Baseline characteristics (values are means \pm standard deviations (SD))

\begin{tabular}{|c|c|c|c|c|}
\hline & \multirow[t]{2}{*}{$\mathbf{N}$} & \multirow{2}{*}{$\begin{array}{l}\text { Hypnosis } \\
N=47 \\
\text { Mean } \pm \text { SD }\end{array}$} & \multirow{2}{*}{$\begin{array}{l}\text { Control } \\
N=48 \\
\text { Mean } \pm \text { SD }\end{array}$} & \multirow{2}{*}{$\begin{array}{l}\text { All participants } \\
N=95 \\
\text { Mean } \pm \text { SD }\end{array}$} \\
\hline & & & & \\
\hline VAS stress level $[\mathrm{mm}]^{\mathrm{a}}$ & 95 & $73.8 \pm 10.1$ & $69.0 \pm 11.3$ & $71.4 \pm 10.9$ \\
\hline Perceived stress (CPSS score) ${ }^{a}$ & 95 & $22.5 \pm 5.1$ & $22.5 \pm 5.9$ & $22.5 \pm 5.5$ \\
\hline Depression (ADS-K score) ${ }^{a}$ & 95 & $26.9 \pm 7.3$ & $27.9 \pm 6.9$ & $27.4 \pm 7.1$ \\
\hline Self-Efficacy (SWE score) ${ }^{b}$ & 95 & $26.3 \pm 5.3$ & $25.2 \pm 4.9$ & $25.7 \pm 5.1$ \\
\hline \multicolumn{5}{|l|}{ SF-36 } \\
\hline Physical Component Summary ${ }^{b}$ & 95 & $52.4 \pm 10.0$ & $50.7 \pm 8.8$ & $51.6 \pm 9.4$ \\
\hline Mental Component Summary ${ }^{b}$ & 95 & $38.0 \pm 9.7$ & $38.4 \pm 10.5$ & $38.2 \pm 10.1$ \\
\hline \multicolumn{5}{|l|}{ SF-36 ${ }^{\text {b }}$ Subscores } \\
\hline Physical functioning & 95 & $90.7 \pm 14.7$ & $91.3 \pm 10.6$ & $91.0 \pm 12.7$ \\
\hline Role limitations due to physical health & 95 & $72.3 \pm 31.8$ & $71.4 \pm 36.8$ & $71.8 \pm 34.3$ \\
\hline Role limitations due to emotional problems & 95 & $56.0 \pm 36.2$ & $61.8 \pm 37.7$ & $59.0 \pm 36.9$ \\
\hline Vitality & 95 & $43.0 \pm 17.0$ & $43.1 \pm 19.5$ & $43.0 \pm 18.2$ \\
\hline Emotional well-being & 95 & $56.9 \pm 14.8$ & $57.5 \pm 15.1$ & $57.2 \pm 14.9$ \\
\hline Social functioning & 95 & $70.7 \pm 23.9$ & $63.0 \pm 20.9$ & $66.8 \pm 22.7$ \\
\hline Pain & 95 & $76.3 \pm 28.1$ & $67.9 \pm 27.1$ & $72.1 \pm 27.8$ \\
\hline General health & 95 & $61.2 \pm 23.9$ & $59.3 \pm 20.6$ & $60.2 \pm 22.2$ \\
\hline
\end{tabular}

VAS visual analog scale, CPSS Cohen's Perceived Stress Scale, ADS-K Allgemeine Depressions-Skala Kurzform (depression), SWE Selbstwirksamkeitserwartung (selfefficacy), SF-36 Short-Form-Survey (quality of life)

${ }^{\mathrm{a}}$ lower values indicate better status, ${ }^{\mathrm{b}}$ higher values indicate better status 
Table 4 Primary and secondary outcomes at week 5 for the hypnosis and control groups, means and mean group differences with 95\% confidence interval (Cl), adjusted for respective baseline value and center

\begin{tabular}{|c|c|c|c|c|c|}
\hline & & Hypnosis & Control & Control vs Hypnosis & \\
\hline & $\mathbf{N}$ & $\begin{array}{l}\text { Adjusted mean } \\
(95 \% \mathrm{Cl})\end{array}$ & $\begin{array}{l}\text { Adjusted mean } \\
(95 \% \mathrm{Cl})\end{array}$ & $\begin{array}{l}\text { Adjusted mean difference } \\
(95 \% \mathrm{Cl})\end{array}$ & $P$ value \\
\hline$\overline{\text { VAS stress intensity }[\mathrm{mm}]^{\mathrm{a}}}$ & 88 & $41.8(35.2 ; 48.4)$ & $62.9(56.2 ; 69.7)$ & $-21.2(-30.1 ;-12.2)$ & $<.001$ \\
\hline Perceived stress (CPSS score) ${ }^{a}$ & 88 & $14.7(13.1 ; 16.3)$ & $20.3(18.7 ; 22.0)$ & $-5.7(-7.8 ;-3.5)$ & $<.001$ \\
\hline Depression (ADS-K score) ${ }^{a}$ & 88 & $20.3(18.5 ; 22.1)$ & $25.1(23.3 ; 26.9)$ & $-4.9(-7.2 ;-2.5)$ & 0.001 \\
\hline Self-Efficacy (SWE score) ${ }^{b}$ & 88 & $30.00(28.9 ; 31.1)$ & $26.6(25.5 ; 27.7)$ & $3.4(2.0 ; 4.9)$ & $<.001$ \\
\hline$S F-36^{b}$ & & & & & \\
\hline Physical Component Summary ${ }^{b}$ & 88 & $51.6(49.6 ; 53.6)$ & $51.8(49.8 ; 53.8)$ & $-0.3(-2.9 ; 2.4)$ & 0.848 \\
\hline Mental Component Summary ${ }^{\mathrm{b}}$ & 88 & $48.4(45.7 ; 51.1)$ & $39.2(36.5 ; 41.9)$ & $9.2(5.6 ; 12.8)$ & $<.001$ \\
\hline SF-36 ${ }^{\mathrm{b}}$ Subscores & & & & & \\
\hline Physical functioning & 88 & $90.8(87.9 ; 93.8)$ & $91.1(88.1 ; 94.1)$ & $-0.3(-4.2 ; 3.7)$ & 0.897 \\
\hline Role limitations due to physical health & 88 & $83.0(73.8 ; 92.2)$ & $72.8(63.6 ; 82.1)$ & $10.2(-2.0 ; 22.4)$ & 0.101 \\
\hline Role limitations due to emotional problems & 88 & $80.1(70.1 ; 90.0)$ & $58.9(48.8 ; 69.0)$ & $21.2(7.9 ; 34.6)$ & 0.002 \\
\hline Vitality & 88 & $60.1(54.5 ; 65.6)$ & $42.1(36.4 ; 47.7)$ & $18.0(10.6 ; 25.4)$ & $<.001$ \\
\hline Emotional well-being & 88 & $73.7(69.4 ; 78.1)$ & $59.7(55.3 ; 64.1)$ & $14.0(8.3 ; 19.8)$ & $<.001$ \\
\hline Social functioning & 88 & $82.7(76.8 ; 88.7)$ & $72.62(66.7 ; 78.5)$ & $10.1(2.2 ; 18.1)$ & 0.013 \\
\hline Pain & 88 & $79.7(73.3 ; 86.00)$ & $74.2(68.0 ; 80.3)$ & $5.5(-2.9 ; 13.9)$ & 0.200 \\
\hline General health perception & 88 & $68.7(64.1 ; 73.4)$ & $61.2(56.5 ; 65.8)$ & $7.6(1.4 ; 13.7)$ & 0.017 \\
\hline
\end{tabular}

CI confidence interval, VAS visual analog scale, CPSS Cohen's Perceived Stress Scale, ADS-K Allgemeine Depressions-Skala Kurzform (depression), SWE Selbstwirksamkeitserwartung (self-efficacy), SF-36 Short-Form-Survey (quality of life)

${ }^{a}$ lower values indicate better status, ${ }^{\mathrm{b}}$ higher values indicate better status

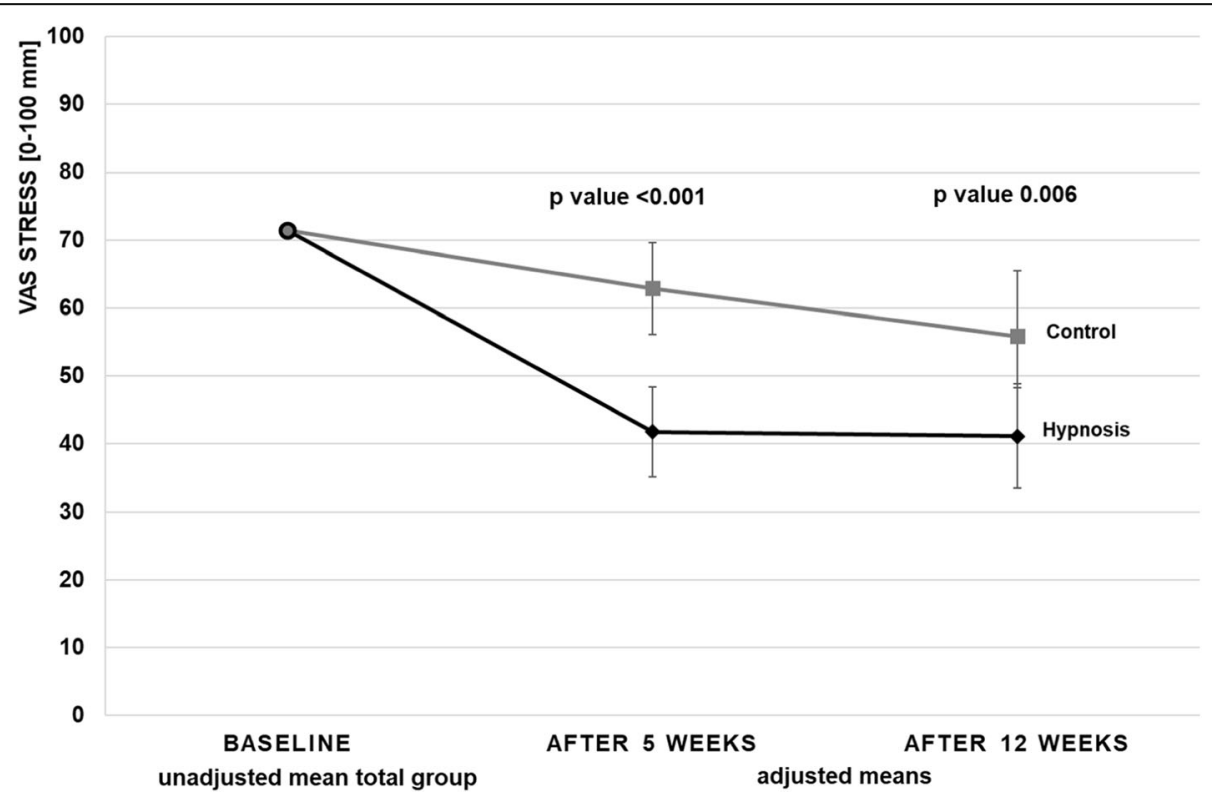

Fig. 2 VAS = Visual Analogue Scale Stress ( $\mathrm{mm}$ ) at baseline (unadjusted mean of total group), after 5 weeks (primary outcome) and after 12 weeks (secondary outcome; both adjusted for respective baseline value and center) for hypnosis and control group 
Table 5 Primary and secondary outcomes at week 12 for the hypnosis and control groups, means and mean group differences with 95\% confidence interval (Cl), adjusted for respective baseline value and center

\begin{tabular}{|c|c|c|c|c|c|}
\hline & & Hypnosis & Control & Control vs Hypnosis & \\
\hline & $\mathbf{N}$ & $\begin{array}{l}\text { Adjusted mean } \\
(95 \% \mathrm{Cl})\end{array}$ & $\begin{array}{l}\text { Adjusted mean } \\
(95 \% \mathrm{Cl})\end{array}$ & $\begin{array}{l}\text { Adjusted mean difference } \\
(95 \% \mathrm{Cl})\end{array}$ & $P$ value \\
\hline VAS stress intensity [mm] ${ }^{a}$ & 90 & $41.1(33.5 ; 48.8)$ & $55.9(48.2 ; 63.5)$ & $-14.7(-25.1 ;-4.4)$ & 0.006 \\
\hline Perception of stress (CPSS score) ${ }^{a}$ & 89 & $13.8(12.1 ; 15.4)$ & $19.0(17.3 ; 20.6)$ & $-5.2(-7.4 ;-3.0)$ & $<.001$ \\
\hline Depression (ADS-K score) ${ }^{a}$ & 89 & $20.6(18.9 ; 22.4)$ & $25.4(23.7 ; 27.1)$ & $-4.8(-7.1 ;-2.5)$ & $<.001$ \\
\hline Self-Efficacy (SWE score) ${ }^{b}$ & 89 & $29.7(28.6 ; 30.8)$ & $26.4(25.2 ; 27.5)$ & $3.3(1.8 ; 4.9)$ & $<.001$ \\
\hline SF-36 ${ }^{\mathrm{b}}$ & & & & & \\
\hline Physical Component Summary ${ }^{\mathrm{b}}$ & 90 & $51.2(48.9 ; 53.4)$ & $51.4(49.2 ; 53.5)$ & $-0.2(-3.1 ; 2.7)$ & 0.895 \\
\hline Mental Component Summary ${ }^{\mathrm{b}}$ & 90 & $49.3(46.5 ; 52.2)$ & $40.2(37.4 ; 43.0)$ & $9.1(5.3 ; 12.8)$ & $<.001$ \\
\hline SF-36 ${ }^{\mathrm{b}}$ Subscores & & & & & \\
\hline Physical functioning & 90 & $90.4(87.2 ; 93.7)$ & $89.9(86.8 ; 93.1)$ & $0.5(-3.8 ; 4.7)$ & 0.829 \\
\hline Role limitations due to physical health & 90 & $87.9(79.7 ; 96.1)$ & $73.9(65.9 ; 81.9)$ & $14.0(3.3 ; 24.8)$ & 0.011 \\
\hline Role limitations due to emotional problems & 90 & $90.2(80.5 ; 99.9)$ & $67.2(57.6 ; 76.8)$ & $23.0(10.2 ; 35.9)$ & 0.001 \\
\hline Vitality & 90 & $58.7(52.8 ; 64.5)$ & $44.4(38.7 ; 50.2)$ & $14.2(6.5 ; 21.9)$ & 0.001 \\
\hline Emotional well-being & 90 & $74.6(70.0 ; 79.2)$ & $59.5(55.0 ; 64.0)$ & $15.1(9.1 ; 21.1)$ & $<.001$ \\
\hline Social functioning & 90 & $79.4(72.4 ; 86.3)$ & $70.0(63.3 ; 76.7)$ & $9.4(0.2 ; 18.5)$ & 0.046 \\
\hline Pain & 90 & $78.9(71.8 ; 86.1)$ & $72.2(65.4 ; 79.0)$ & $6.7(-2.7 ; 16.1)$ & 0.160 \\
\hline General health perception & 90 & $69.1(64.6 ; 73.6)$ & $63.8(59.3 ; 68.2)$ & $5.4(-0.6 ; 11.3)$ & 0.075 \\
\hline
\end{tabular}

CI confidence interval, VAS visual analog scale, CPSS Cohen's Perceived Stress Scale, ADS-K Allgemeine Depressions-Skala Kurzform (depression), SWE Selbstwirksamkeitserwartung (self-efficacy), SF-36 Short-Form-Survey (quality of life)

${ }^{a}$ lower values indicate better status, ${ }^{\mathrm{b}}$ higher values indicate better status

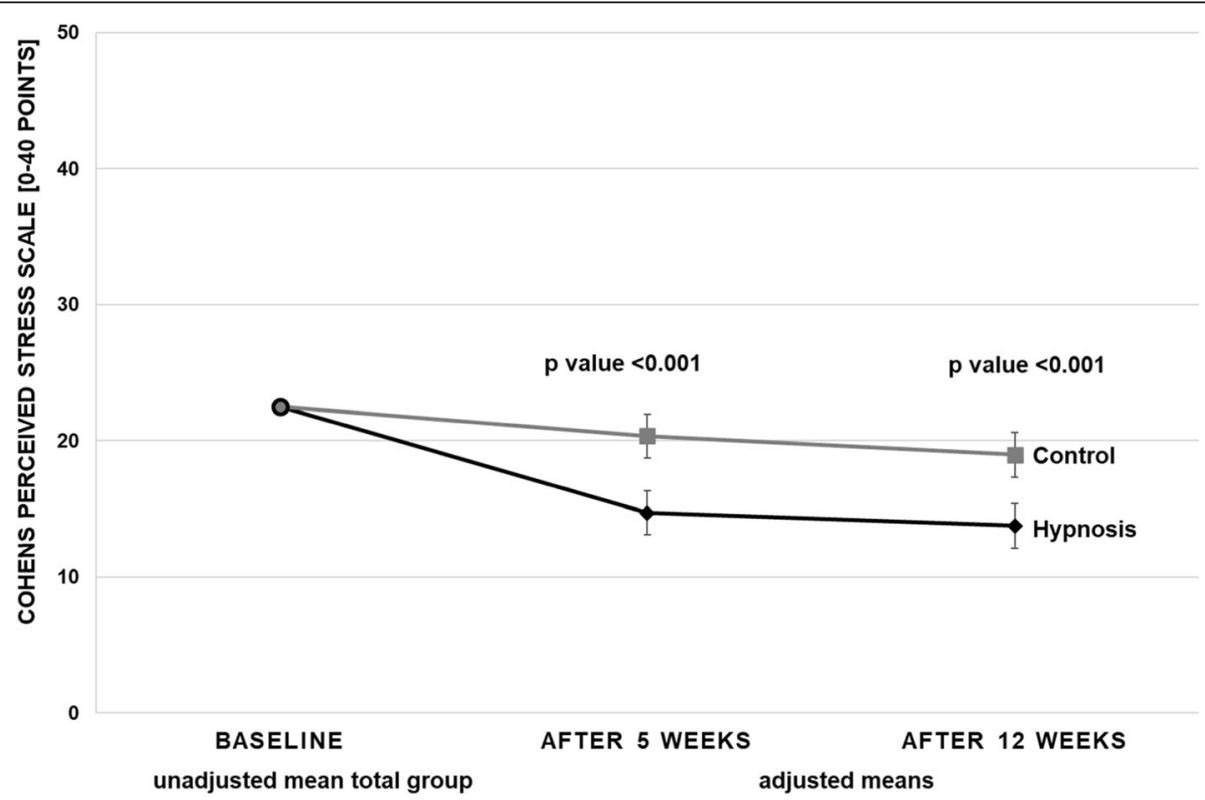

Fig. 3 Cohen's Perceived Stress Scale at baseline (unadjusted mean of total group) and after 5 weeks and 12 weeks (secondary outcome; both adjusted for respective baseline value and center) in the hypnosis and control groups 


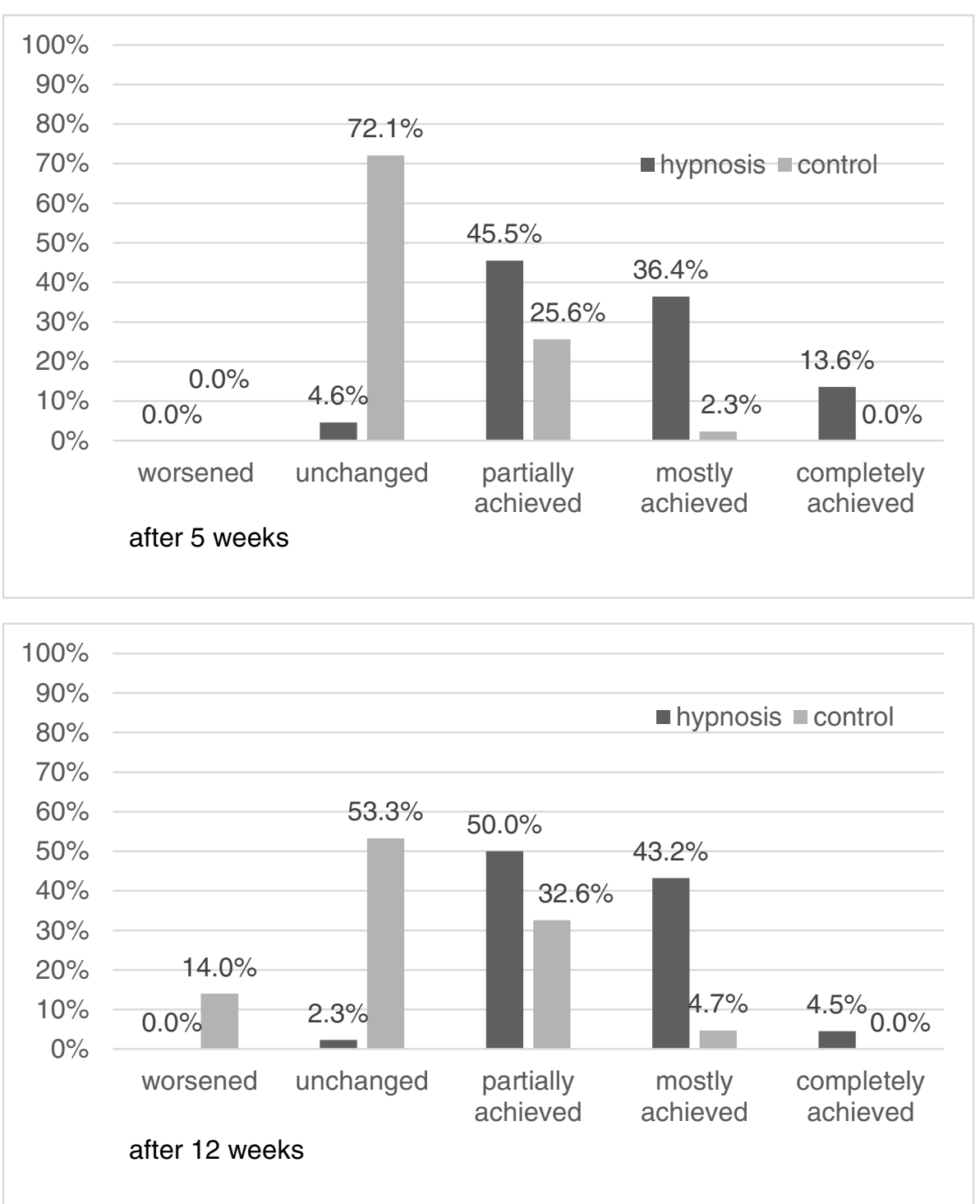

Fig. 4 Personal goal attainment after 5 weeks. Percentages

compare the hypnotizability in both groups to examine a potential effect of hypnotizability as a moderator variable.

In contrast to other hypnosis studies on stress reduction [38-41], we did not assess laboratory data. This could be considered a weakness of our study, but we deliberately focused on patient-centered clinical outcomes. However, given the lack of blinding, physiological measurable stress variables would have been an additional tool for objectifying the assessment of stress. Furthermore the fact that the physician and psychotherapists who conducted the group programs also assessed the inclusion and exclusion criteria and health status at baseline, may have introduced some aspect of assessment bias.

A comparison of the data from the present study with the data of our sample from the feasibility study shows many similarities. In our former feasibility study, pre/post improvements in stress reduction (VAS stress intensity), perceived stress (CPSS score), depression (ADS-K) and quality of life (SF-36 Mental Component Summary) were reported. Additionally, in the SF-36 questionnaire, participants showed considerable improvements on the same subscores as in our current study, especially vitality and emotional well-being. The personal goal attainment measured by a Likert scale was similarly high in our previous study, in which $50 \%$ of the participants stated partially reaching their personal main goal and an additional 50\% mostly or completely achieving their main goal. The satisfaction with the program was high as well $(16.7 \%$ of the participants were satisfied and $83.3 \%$ were very satisfied) [5]. Thus, we could largely confirm the hypotheses derived from the exploratory results of our pilot study. 
With a baseline ADS-K score of 27.4 \pm 7.1 , the overall sample showed a relatively high level of depression, which would be in line with the hypothesis that increased levels of subjective stress are often associated with depressive symptoms and can be considered a risk factor for developing a depressive disorder [48-52]. Also the frequency of participants that showed an increased level of depression with an ADS-K score > 17 at baseline was high with 93.6\% of the hypnosis group and $89.6 \%$ of the control group, respectively. The fact that a difference in the degree of depression between the hypnosis group participants and the control group could be demonstrated after 5 weeks and 12 weeks, and that the frequency of ADS-K scores $>17$ in the hypnosis group was reduced after 5 and 12 weeks compared to the control group allows the hypothesis that the hypnotherapeutic group program may be a useful tool for preventing the development of depressive symptoms.

In our study we found that the hypnosis program plus the behavioral stress management educational booklet was superior to the educational booklet alone in terms of reducing stress and improving stress coping. So the program could be useful if physicians and psychotherapists who have the appropriate hypnosis qualification could provide such a preventive stress reduction program in health education.

In German-speaking countries, a number of manualized, scientifically evaluated stress management trainings are available that are based on a cognitive-behavioral approach [6-11]. Usually, they combine psychoeducation modules, relaxation, time management, problem-solving training, enjoyment training, and cognitive restructuring. Overall, the research evidence has been positive for the effectiveness of these trainings [1]. A systematic review of 116 RCT studies, including multimodal training programs for the self-management of emotional stress, have demonstrated positive effects of cognitive behavioral stress management and cognitive behavioral therapy-based programs [12]. In addition, mindfulness-based stress reduction (MBSR) interventions [53, 54], are receiving increased attention. In meta-analyses, positive evidence has been found for stress reduction [55-57]. MBSR includes elements of instruction on mindfulness meditation, group dialogue aimed at enhancing awareness in everyday life and elements of mindful yoga.

Further studies should compare the effectiveness of this program with already established stress reduction programs (based on cognitive-behavioral therapy or MBSR) in noninferiority trials. Additionally, basic research should explore the neurophysiological mechanisms of hypnosis in preventing and reducing stress. Furthermore, it would be interesting to assess more laboratory data as indicators for stress- and stress-related health factors (such as blood pressure and hormonal status). Additionally, the effectiveness in preventing a depressive disorder should be tested in further studies.

\section{Conclusion}

In this multicenter randomized controlled trial, participants in a hypnotherapeutic group program for stress reduction and improved stress coping showed reduced perceived psychological stress measured by a visual analogue scale, Cohen's Perceived Stress Scale, also reduction of depression scale and improved quality of life compared to individuals in a control group.

\section{Abbreviations}

ADS-K: Allgemeine Depressionsskala Kurzform [General Depression Scale shortform]; Cl: confidence interval; CPSS: Cohen's Perceived Stress Scale; FAS: full analysis set; HADS: Hospital Anxiety and Depression Scale; ITT: intention-to-treat; MBSR: mindfulness-based stress reduction; N: numbers; p: probabilitas, probability; SAP: statistical analysis plan; SD: standard deviations; SF-36: Short-Form-Survey (quality of life);

SWE: Selbstwirksamkeitserwartung [self-efficacy]; RCT: randomized controlled trial; VAS: visual analogue scale

\section{Acknowledgments}

We thank Prof. Dr. Dipl.-Psych. Walter Bongartz, Dr. Dipl-Psych. Helga HüskenJanßen, Dipl.-Psych. Norbert Loth, Prof. Dr. Dipl.-Psych. Dirk Revenstorf and Dr. Dipl.-Psych. Ronald Zeyer for valuable help and their expert advice in designing the intervention.

\section{Authors' contributions}

SF, MT and BB developed the research idea and the methodology, and SF developed the hypnotherapeutic group program, which was reviewed by MT. MC and SB handled and organized the data, SF, MT and ST conducted the group program, SB, TK and SR performed the statistical data analysis, SF, SB, SR, TK and MT discussed the statistical results, SF wrote the first draft of the manuscript, and MT and BB primarily edited the manuscript. All authors have read and commented on the final draft.

\section{Funding}

This study was an investigator-initiated study. We received a small funding support by a Crowdfunding Campaign (https://www.betterplace.org/de/projects/55653?utm_campaign=ShortURLs\&utm_medium=project_55653\&utm_ source=PlainShortURL).

The people funding the study and also the crowdfunding platform had no influence on the design and methodology of the study, the data collection, analysis or interpretation, or the preparation of the manuscript. Open Access funding enabled and organized by Projekt DEAL.

\section{Availability of data and materials}

The study protocol, the datasets used and/or analyzed during the current study are available from the corresponding author upon reasonable request. The hypnosis instructions used during the current study is already accepted for publication as a manual at Klett-Cotta, Imprint Schattauer publishers and will be published and available in 2021. The working title is "HypnoStressbewältigung - ein hypnotherapeutisches Gruppenprogramm". The study was registered at ClinicalTrials.gov (NCT03525093) [58].

\section{Ethics approval and consent to participate}

The study was approved by the ethics committee of the Charité Universitätsmedizin Berlin (EA1/067/18 20/04/2018). Written informed consent was obtained from all participants before inclusion into the trial.

\section{Consent for publication}

All authors provided their consent to publish before the publication of the work.

\section{Competing interests}

MT and SF are both members of the Deutsche Gesellschaft für Hypnose und Hypnotherapy (DGH) and certified hypnotherapists who received payments for teaching hypnosis within the hypnotherapy training programs of the DGH in the past. All other authors declare that they have no conflicts of interest. 


\section{Author details}

'Psychotherapeutische Praxis, Daruper Str. 14, 48653 Coesfeld, Germany. ${ }^{2}$ Institute for Social Medicine, Epidemiology, and Health Economics, Charité -Universitätsmedizin Berlin, Luisenstr. 57, 10117 Berlin, Germany. ${ }^{3}$ MEDIAN Zentrum für Verhaltensmedizin Bad Pyrmont - Klinik für Psychosomatik, Bombergallee 10, 31812 Bad Pyrmont, Germany. ${ }^{4}$ Institute of Biometry and Clinical Epidemiology, Charité-Universitätsmedizin Berlin, Charitéplatz 1, 10117 Berlin, Germany.

\section{Received: 10 January 2020 Accepted: 22 October 2020}

\section{Published online: 13 November 2020}

\section{References}

1. Heinrichs M, Stächele T, Domes G. Stress und Stressbewältigung. Hogrefe Verlag: Göttingen; 2015.

2. Anderson NB, Bennett Johnson S, Belar CD, Breckler SJ, Nordal KC, Ballard D, et al. Stress in America: our health at risk. Washington, DC: American Psychological Association; 2012. www.apa.org/news/press/ releases/stress/2011/final-2011.pdf.

3. Nier H. Gestresste Arbeitnehmer. Statista. https://de.statista.com/ infografik/13752/gestresste-arbeitnehmer-in-europa/. 2018.

4. Wohlers K, Hombrecher M. Entspann dich, Deutschland TK-Stressstudie 2016. Hamburg: Techniker Krankenkasse; 2016.

5. Fisch S, Cree M, Binting S, Roll S, Teut M, Brinkhaus B. Group-hypnosis for stress reduction - a feasibility study. Int J Clin Exp Hypn. 2020;68(4):493-510.

6. Meichenbaum D. Intervention bei Stress: Anwendung und Wirkung des Stressimpfungstrainings. 3 ed. Bern: Huber; 2012.

7. Schelp T, Gravemeier R, Maluck D. Rational-emotive Therapie als Gruppentraining gegen Streß. Seminarkonzepte und Materialien. Bern: Huber; 1997.

8. Kaluza G. Gelassen und sicher im Stress. Psychologisches Programm zur Gesundheitsförderung. Berlin: Springer; 1996.

9. Wagner-Link A. Verhaltenstraining zur Stressbewältigung. Arbeitsbuch für Therapeuten und Trainer. Stuttgart: Klett-Cotta Verlag; 2010

10. Reschke K, Schröder H. Optimistisch den Stress meistern. Tübingen. Tübingen: DGVT-Verlag; 2000.

11. Müller $\mathrm{H}$, Kröger CB. Der erfolgreiche Umgang mit täglichen Belastungen. Programm zur Stressbewältigung. 6 ed. München: IFT; 2013.

12. Crawford C, Wallerstedt DB, Khorsam R, Clausen SS, Jonas WB, Walter JAG. A systematic review of biopsychosocial training programs for the selfmanagement of emotional stress: potential applications for the military. Evid Based Complement Alternat Med. 2013;2013:23.

13. Häuser W, Hagl M, Schmierer A, Hansen E. The efficacy, safety and applications of medical hypnoses. Dtsch Arztebl Int. 2016;113(17):289-96.

14. Adachi T, Fujino H, Nakae A, Mashimo T, Sasaki J. A meta-analysis of hypnosis for chronic pain problems: a comparison between hypnosis, standard care, and other psychological interventions. Int J Clin Exp Hypn. 2014;62(1):1-28

15. Elkins GR, Barabasz AF, Council JR, Spiegel D. Advancing research and practice: the revised APA division 30 definition of hypnosis. Int J Clin Exp Hypn. 2014;63(1):1-9.

16. Fisch S, Brinkhaus B, Teut M. Hypnosis in patients with perceived stress - a systematic review. BMC Complementary Alternative Med. 2017:17(1):323. https://doi.org/10.1186/s12906-017-1806-0. PMID: 28629342; PMCID: PMC5477290

17. Revenstorf D, Peter B. Hypnose in Psychotherapie, Psychosomatik und Medizin. 3. ed. Heidelberg: Springer; 2015.

18. Stangl W. Online Lexikon für Psychologie und Pädagogik. 2019.https:// lexikon.stangl.eu/1316/hypnose-hypnotherapie. Accessed 15 Apr 2019.

19. Wagner-Link A. Stress Belastungen besser bewältigen. Techniker Krankenkasse, editor. Hamburg: Techniker Krankenkasse; 2017.

20. Zarren J, Eimer B. Self-Hypnosis for Contiued Problem Resolution. In: Zarren J, Eimer B, editors. Brief Cognitive Hypnosis: Facilitating the Change of Dysfunctional Behavior (pp. 78-89). Springer Publishing Company; 2002.

21. Zeyer R. Hypnotherapeutische Strategien bei akutem und chronischem Stress. Heidelberg: Carl-Auer Verlag; 2012

22. Stanton HE. The reduction in secretarial stress. Contemporary Hypnosis. 1991:8(1):45-55.

23. Hüsken-Janßen H. Hypnotherapeutische Geburtsvorbereitung. Studie zur Wirksamkeit der hypnoreflexogenen Methode nach Schauble. Frankfurt am Main: Peter Lang; 2005
24. Revenstorf D, Zeyer R. Hypnose lernen. Leistungssteigerung und Streßbewältigung durch Selbsthypnose. 7 ed. Heidelberg: Carl-Auer; 2006.

25. Stanton HE. Hypnosis and rational-emotive therapy - a de-stressing combination: a brief communication. Int J Clin Exp Hypn. 1989:37(2):95-9.

26. Bongartz W. Ressourcenarbeit. In: Kaiser Rekkas a, editor. Hypnose und Hypnotherapie. Manual für praxis, Forbildung und Lehre. Modul 2: Aufbaukurs. (pp. 166-171). Heidelberg: Carl-Auer; 2018.

27. Zarren J, Eimer B. Trance induction: design, choice, and administration. In: Zarren J, Eimer B, editors. Brief cognitive hypnosis: facilitating the change of dysfunctional behavior (pp. 58-77). USA: Springer Publishing Company; 2002

28. Lesage BS. Validity of occupational stress assessment using a visual analogue scale. Occup Med. 2011;61(6):434-6.

29. Lesage B. S, Deschamps F. clinical stress assessment using a visual analogue scale. Occup Med. 2012;62(8):600-5.

30. Zigmond AS, Snaith RP. The hospital anxiety and depression scale. Acta Psychiatr Scand. 1983:67:361-70.

31. Cohen S, Kamarck T, Mermelstein R. A global measure of perceived stress. J Health Soc Behav, 1983:24(4):385-96.

32. Büssing A. Translation of Cohen's 10 item Perceived Stress Scale (PSS). University of Witten/Herdecke (arndtbuessing@uni-whde); 2011.

33. Hautzinger M, Bailer M, Hofmeister D, Keller F. Allgemeine Depressionsskala (ADS-K). Göttingen: Hogrefe; 2012.

34. Schwarzer R, Jerusalem M. Skalen zur Erfassung von Lehrer- und Schülermerkmalen. Dokumentation der psychometrischen Verfahren im Rahmen der Wissenschaftlichen Begleitung des Modellversuchs Selbstwirksame Schulen. Berlin: Freie Universität Berlin; 1999.

35. Bullinger M, Kirchberger I. SF-36 Fragebogen zum Gesundheitszustand. Göttingen: Hogrefe; 1998.

36. Bullinger M. Erfassung der gesundheitsbezogenen Lebensqualität mit dem SF-36-Health Survey. Bundesgesundheitsbl Gesundheitsforsch Gesundheitsschutz. 2000:43(3):190-7.

37. Cardeña E, Svensson C, Hejdstrom F. Hypnotic tape intervention ameliorates stress: a randomized, control study. Int J Clin Exp Hypn. 2013;61(2):125-45.

38. Gruzelier J, Smith F, Nagy A, Henderson D. Cellular and humoral immunity, mood and exam stress: the influences of self-hypnosis and personality predictors. Int J Psychophysiol. 2001;42(1):55-71.

39. Kiecolt-Glaser JK, Glaser R, Strain EC, Stout JC, Tarr KL, Holliday JE, et al. Modulation of cellular immunity in medical students. J Behav Med. 1986; 9(1):5-21.

40. Kiecolt-Glaser JK, Marucha PT, Atkinson C, Glaser R. Hypnosis as a modulator of cellular immune dysregulation during acute stress. J Consult Clin Psychol. 2001:69(4):674-82

41. Naito A, Laidlaw TM, Henderson DC, Farahani L, Dwivedi P, Gruzelier JH. The impact of self-hypnosis and Johrei on lymphocyte subpopulations at exam time: a controlled study. Brain Res Bull. 2003;62(3):241-53.

42. Whitehouse WG, Dinges DF, Orne EC, Keller SE, Bates BL, Bauer NK, et al. Psychosocial and immune effects of self-hypnosis training for stress management throughout the first semester of medical school. Psychosom Med. 1996:58(3):249-63.

43. Pfitzer BE, Clark K, Revenstorf D. [medical hypnosis in cases of herpes labialis improves resistance for recurrence. A pilot study]. Der Hautarzt. Zeitschrift fur Dermatologie, Venerologie, und verwandte Gebiete. 2005:56(6):562-8.

44. Faymonville ME, Mambourg PH, Joris J, Vrijens B, Fissette J, Albert A, et al. Psychological approaches during conscious sedation. Hypnosis versus stress reducing strategies: a prospective randomized study. Pain. 1997;73(3):361-7.

45. Swirsky-Sacchetti T, Margolis CG. The effects of a comprehensive selfhypnosis training program on the use of factor VIII in severe hemophilia. Int J Clin Experimental Hypnosis. 1986;34(2):71-83.

46. Taylor DN. Effects of a behavioral stress-management program on anxiety, mood, self-esteem, and T-cell count in HIV positive men. Psychol Rep. 1995; 76(2):451-7

47. Crowe M, Jordan J, Burrell B, Jones V, Gillon D, Harris S. Mindfulness-based stress reduction for long-term physical conditions: a systematic review. Aust N Z J Psychiatry. 2015:1-12.

48. Lazarus RS. Emotion and adaption. New York: Oxford University Press; 1991.

49. Abramson LY, Metalsky Gl, Alloy LB. Hopelessness depression: a theorybased subtype of depression. Psychol Rev. 1989:96:358-72.

50. Metalsky Gl, Joiner TE, Hardin TS, Abramson LY. Depressive reactions to failure in a naturalistic setting: a test of the hopelessness and self-esteem theories of depression. J Abnorm Psychol. 1993;102:101-9. 
51. Hautzinger M. Akute Depression. Schulte D, Hahlweg K, Margraf J, Vaitl D, editors. Göttingen: Hogrefe; 2010

52. Murray CJ, Lopez AD. Global mortality, disability, and the contribution of risk factors. Global burden of disease study. Lancet. 1997;348:1436-42.

53. Kabat-Zinn J. Full catastrophe living: using the wisdom of your body and mind to face stress, pain and illness. New York: Delacorte; 1990.

54. Kabat-Zinn J. Mindfulness-Based Interventions in Context: Past, Present, and Future. Clin Psychol Sci Pract. 2003;10:144-56. https://doi.org/10. 1093/clipsy.bpg01.

55. Chiesa A, Seretti A. Mindfulness-based stress reduction for stress management in healthy people: a review and meta-analysis. J Altern Complement Med. 2009;15(5):593-600. https://doi.org/10.1089/acm. 2008.0495.

56. Grossmann P, Niemann L, Schmidt S, Walach H. Mindfulness-based stress reduction and health benefits. A meta-analysis. J Psychosom Res. 2004:57(1): 35-43. https://doi.org/10.1016/50022-3999(03)00573-7.

57. Berking $M$, Känel M. Achtsamkeitstraining als psychotherapeutische Interventionsmethode. Psychother Psychosom Med Psychol. 2007; 57(3/04):170-7.

58. ClinicalTrials.gov Identifier: NCT03525093; https://clinicaltrials.gov/ct2/show/ NCT03525093. Accessed 27 Oct 2020

\section{Publisher's Note}

Springer Nature remains neutral with regard to jurisdictional claims in published maps and institutional affiliations.

Ready to submit your research? Choose BMC and benefit from:

- fast, convenient online submission

- thorough peer review by experienced researchers in your field

- rapid publication on acceptance

- support for research data, including large and complex data types

- gold Open Access which fosters wider collaboration and increased citations

- maximum visibility for your research: over $100 \mathrm{M}$ website views per year

At BMC, research is always in progress.

Learn more biomedcentral.com/submissions 